\title{
Brain slice culture for analysis of developmental brain disorders with special reference to congenital cytomega- lovirus infection
}

\author{
Hideya Kawasaki and Yoshihiro Tsutsui \\ Second Department of Pathology, Hamamatsu University School of Medicine, Hamamatsu, Japan
}

\begin{abstract}
Cytomegalovirus (CMV) is the most significant infectious cause of congenital abnormalities of the central nervous system (CNS) with variation from the fatal cytomegalic inclusion disease to functional brain disorder. The phenotype and degree of the brain disorder depends on infection time during the developing stage, virulence, route of infection and the viral susceptibility of the cells. The pathogenesis of the CMV infection to the CNS seems to be strongly related to neural migration, neural death, cellular compositions and the immune system of the brain. To understand the complex mechanism of this disorder, we used organotypic brain slice cultures. In the brain slice culture system, migration of CMV-infected neuronal cells was observed, which reflects infectious dynamics in vivo. Neural progenitor cells or glial immature cells in the subventricular zone and marginal area are most susceptible to murine cytomegalovirus (MCMV) infection in this system. The susceptibility declined as the number of immature glial cells decreased with age. The immature glial cells proliferated in brain slice cultures during prolonged incubation, and the susceptibility to MCMV infection also increased in association with the proliferation of these cells. The brain slice from an immunocompromised mouse (Beige-SCID mouse) unexpectedly showed lower susceptibility than that of an immunocompetent mouse during any prolonged incubation. These results suggest that the number of immature glial cells might determine the susceptibility of CMV infection to the brain, independent of the immune system. We reviewed recent findings of $\mathrm{CMV}$ infection to the brain from the perspective of brain slice cultures and the possibility that this system could be a useful method to investi-
\end{abstract}

Correspondence: Dr. Hideya Kawasaki, Second Department of Pathology, Hamamatsu University School of Medicine, 1-20-1 Handayama, Hamamatsu 431-3192, Japan. E-mail: <gloria@hama-med.ac.jp>

Received December 27, 2002; revised and accepted January 17, 2003. gate mechanisms of congenital anomaly of the brain.

Key Words: brain slice culture, congenital cytomegalovirus infection, developmental brain disorder

\section{INTRODUCTION}

Cytomegalovirus (CMV) is the most significant infectious cause of congenital anomalies of the central nervous system (CNS). It is caused by an intrauterine infection in humans (Weller, 1971; Ho, 1991), with an average incidence of $1 \%$ of all live births (Stagno et al., 1986; Demmler, 1991). It is estimated that approximately $5-10 \%$ of infected infants have generalized cytomegalic inclusion disease at birth, with symptoms such as microcephaly, perivascular calcification, and microphthalmia (Becroft, 1981; Bale, 1984; Cinque et al., 1997). Another $10 \%$ of infected infants have subclinical congenital infection, and will subsequently suffer from brain disorders, including mental retardation, sensorineural hearing loss, visual disorders, seizures and epilepsy (Pass et al, 1980; Conboy et al, 1986).

Because studies of human subjects have obvious limitations, experiments with animal models for congenital CMV infection have been reported using guinea pig CMV (Kumar and Nankervis, 1978), murine CMV (Tsutsui, 1995) and simian CMV (London et al., 1986). We have developed model systems for brain abnormalities induced by infection of mouse embryos with murine CMV (Tsutsui and Naruse, 1987; Tsutsui et al., 1993; Li and Tsutsui, 2000). To further investigate the pathogenesis of CMV infection in the CNS, we chose the brain slice system. Brain slice cultures provide a useful experimental system because they preserve the three-dimensional architecture and local environment of neurons, glia, microglia, oligodendroglia to a greater extent than dissociated cell cultures while still preserving the ability to perform experimental manipulations and observations (Lo et al., 1994). Organotypic slice cultures of the brain have been used increasingly to study 
the neuronal death, mechanism of cell migration, and function of microglia, myelination, electrophysiological activities, synapse plasticity and virus infectivity. Our group has applied this unique system for the analysis of cytomegalovirus to the brain for the first time (Shinmura et al., 1999). Here we will review the current scientific findings of congenital cytomegalovirus infection to the brain from the perspective of the organotypic brain slice culture.

\section{PREPARATION OF THE BRAIN SLICE}

The whole brain, dissected from a mouse and kept in cold Hanks' balanced salt solution (HBSS; Gibco BRL, Grand Island, N.Y.) on ice (Fig. 1A), was fixed on a stage with instant glue and cut in a coronal direction at $400-\mu \mathrm{m}$ thickness with a microslicer (Dohan EM, Kyoto, Japan) (Fig. 1B). Slices were transferred to porous transparent membranes (Millicell-CM, $0.4 \mathrm{~mm}$; Millipore, Bedford, Mass), which were floated on a culture medium in a six-well plate (Becton Dickinson, Franklin Lakes, N.J.) as reported previously (Shinmura et al., 1999) (Fig. 1C). The medium consisted of $50 \%$ minimum essential medium (MEM; Gibco BRL), 25\% HBSS, 25\% heat-inactivated horse serum (Gibco BRL), supplemented with $6.5 \mathrm{mg} /$ $\mathrm{ml}$ glucose, $0.15 \mathrm{mg} / \mathrm{ml}$ glutamine, $30 \mathrm{mM} \mathrm{NaHCO} 3,100 \mathrm{U} /$ $\mathrm{ml}$ penicillin, and $50 \mu \mathrm{g} / \mathrm{ml}$ streptomycin. The slices were maintained at $37^{\circ} \mathrm{C}$ in a humidified incubator with $95 \%$ air and $5 \% \mathrm{CO}_{2}$.

\section{NEURONAL CELL MIGRATION}

In the brain, neurons usually originate in the ventricular zone, where their precursor cells proliferate. They can then migrate radially to other layers in the brain, or tangentially to other regions of the brain (Rakic, 1990; O'Rourke et al., 1997). A disruption in neuronal migration during central nervous sys-
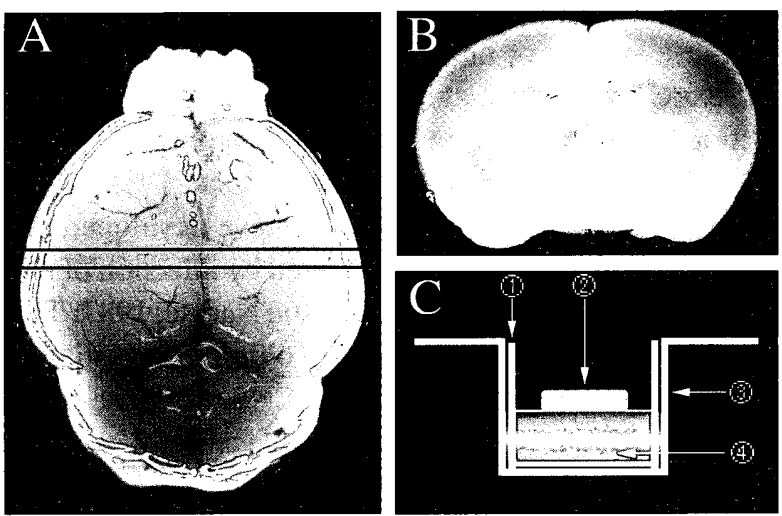

Fig. 1 Preparation of the brain slice. A: The whole brains, dissected from 21-day old mouse. B: Brain slice of $400-\mu \mathrm{m}$ thickness. C: Schematic representation of slice culture. (1) culture insert, (2) cerebral slice, (3) 6-well plate, (4) culture medium. tem development has been postulated as the mode of pathogenesis for many of disorders. Recently, the cell migration hypothesis has been proven for microcehpaly, lissencephaly, subcortical band heterotopia, periventricular nodular heterotopia and cerebral palsy (Tsutsui et al., 1999; Lammens, 2000). Microcephaly, lissencephaly and polymicrogyria have been reported to sometimes be associated with human congenital CMV infection (Bale, 1984; Tsutsui et al., 1997). In animal experiments, developmental retardation with microcephaly was observed in about $25 \%$ of offspring exposed to infection in utero ( $\mathrm{Li}$ and Tsutsui, 2000). Disturbance of the neuronal migration and loss of neurons were observed in the brains of MCMV-infected developing mice in vivo, which were identified by immunohistochemical staining of viral antigen (Shinmura et al., 1997b). Furthermore MCMV-infected and uninfected CNS stem/progenitor cells were transplanted into the neonatal brains. The reduced number of infected stem cells were engulfed into the subventricular zone and expressed GFAP, but did not migrate further, in contrast to the uninfected stem cells (Kosugi et al., 2000).

To observe the migration mechanism of the CMV infected cells of the brain, we used the brain slice culture system. Roberts et al reported that in slice cultures from the neonatal ferret cortex, the initial migration of BrdU-labeled cells into the cortical plate was similar to that in cultured slices and normal animals for the first week. However after 1 week of culture, the labeled cells were distributed more widely than in vivo (Roberts et al., 1993). By using the micromanipulator we have developed procedures for the infection of MCMV to the subventricular zone (SVZ) of brain slice cultures and showed that infected neurons migrate to the cortex in a similar way to that seen in in vivo infection. The infected neuronal cells expressing the early viral antigen migrated from the SVZ to the cerebral cortex, like infected neuronal cells in in vivo

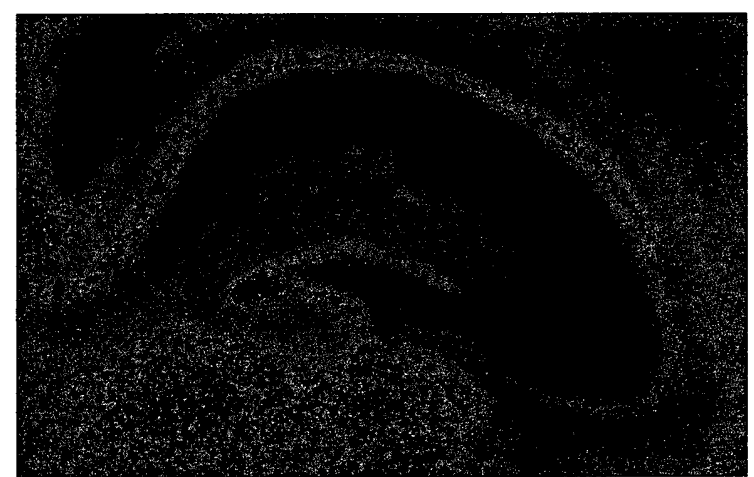

Fig. 2 PI uptake of the hippocampus slice. The hippocampus slice was taken from 21-day old mouse and incubated for 7 days. A final concentration of $2 \mu \mathrm{M}$ PI was added to the culture medium. The cellular uptakes of PI were recorded by fluorescence microscopy $3 \mathrm{~h}$ after the addition of the dye. CA1, CA2 and dentate gyrus (DG) regions had strong intensity of the PI uptake level. 
(Shinmura et al., 1997a), whereas the glial cells preferentially expressing the IE antigen remained in the infected spots detected by X-Gal staining (Shinmura et al, 1999). The neuronal migration of infected cells was not observed in the cerebral slices from 14- and 21-day-old mice. This system may reflect the infectious dynamics in vivo. With the combination of transgenic/knockout animals or functional blocking experiments (by adding drugs or antibodies to the slice) we could obtain more information for further understanding the mechanism of migration disorder of the brain.

\section{NEURONAL CELL DEATH}

Neuronal degeneration or death plays an important role in the congenital anomaly of the brain. Apoptotic neurons and glia were detected in significant numbers in acute CMV encephalitis in humans (DeBias et al., 2002). In our previous study, we showed quantitatively the neuronal cell loss occurred more in MCMV-infected brains compared with neuronal cells of uninfected brains (Shinmura et al., 1997b). Interestingly apoptic cells were detected predominantly in non-viral-infected neuronal cells in in vivo CMV infections (Kosugi et al., 1998).

In recent years, organotypic slice cultures have been used increasingly to study the neuronal death by hypoxia (Pringle et al., 1997), hypoglycemia (Tasker et al., 1992), or a combination of these to mimic ischemia (Breder et al., 2000), excitotoxins (Kristensen et al., 2001), other neurotoxis (Noer et al., 2002), oxidative stress (Moskowitz et al., 2001), and organic solvents including ethanol (Light et al., 2002). In most of these studies, the cellular uptake of the fluorescent dye propidium iodide (PI) has been used as a marker for dying or degenerative cells (Noraberg et al., 1999). Fig. 2 shows the degeneration level of the hippocampus slice from a 21 day old mouse after 7 days of incubation. It shows the strong PI uptake in the CA1, CA2 and dentate gyrus regions. It is possible to measure the extent of neuronal injury and to identify the location of the vulnerability in the brain slices by reading the PI fluorescence staining level (Yin et al., 2002). Making the brain slice itself causes injury and degeneration to the brain slices. To see the genuine degenerative effect of the virus, protein from the virus of interest should be transduced into the brain slice soon after preparation. This can be performed with new technology by making the fusion protein with pep-1 or TAT, and observe the neural degeneration chronologically (Schwarze et al., 1999; Morris et al., 2001).

Many attempts have been made to identify the signal transduction cascades that mediate nerve cell damage in the CNS (Wieloch et al., 1996; Billingsley and Kincaid, 1997). Neuronal injury is associated with alterations in multiple signaling systems, including the protein kinase $\mathrm{C}$ cascades (Durkin et al., 1997), the MAP kinase pathways (Bergmann et al., 2002), the Ca2+/calmodulin-dependent protein kinase cascade (Ghosh and Greenberg, 1995), the nitric oxide signaling sys- tem (Strijbos et al., 1996), mitochondoria toxins (Luetjens et al., 2000), and caspase signaling system (Yuan and Yankner, 2000). Treatment with the inhibitors of these signaling pathways in the brain slice makes it possible to analyze the neuronal-death-pathway triggered. Ruden et al reported that MAP kinase inhibitor protected the brain slice from neural degeneration triggered by okadaic acid (Runden et al., 1998). Brain slice culture is a powerful method to find neuroprotective drugs or treatment against many different conditions, including $\mathrm{CMV}$, of the developing brain.

\section{SUSCEPTIBILITY OF THE CYTOMEGA- LOVIRUS TO THE BRAIN}

The critical period of insult and the type of disorder mechanism can determine the phenotype of congenital anomaly of the brain. Investigation of the susceptibility of CMV to the brain from developmental viewpoints would help to elucidate the pathology and treatment of this disease. The susceptibility of mice to MCMV infection in vivo has been reported to diminish with age (Hayashi et al., 1985; Tsutsui, 1995). The resistance is thought to be due to development of host defense mechanisms such as those mediated by natural killer (NK) cells (Brutkiewicz and Welsh, 1995) and macrophages (Booss et al., 1989). Standardizing experimental conditions for in vivo analysis of brain susceptibility to viral infections is rather difficult. However, the susceptibility of cells to the CMV infection in vivo is markedly different from that in vitro (Britt and Alford, 1996). It should be noted that analysis of isolated cultured cells may not reflect the phenomena that occur in vivo in terms of in situ cellular interactions and defense responses. We have reported the effects of murine cytomegalovirus (MCMV) infection on the developing mouse brain in terms of susceptible cells and age-related resistance to MCMV in brain slice cultures (Shinmura et al., 1999; Kawasaki et al., 2002). Fig. 3 shows that brain slice cultures from 0-day-old and 21-day-old BALB/c mice were infected with recombinant MCMV $(\mathrm{RM} 461)\left(5 \times 10^{6} \mathrm{PFU} / \mathrm{ml}\right)$ by whole immersion, and cultured for 3 (Figs. 3A and 3C) or 5 days (Figs. 3B and 3D). The brain slices were fixed and stained with $X-G a l$ (5-bromo-4-chloro-3-indolyl- $\beta$-galactoside), and b-Gal ( $\beta$-galactosidase) expression was visualized as blue spots. Staining of cells by X-Gal indicates expression of the late gene of MCMV in these cells. In the 0-day-old slices, virus-infected cells were scattered throughout the slices (Figs. 3A and 3B). In the 21-day-old slices, virus-infected cells tended to be localized in the marginal regions of the cortex and around the ventricles (Figs. 3C and 3D). The number of infected cells stained with X-Gal decreased with increasing age. Virus-infected cells were double-stained with antibodies to stem cell markers such as nestin (Fig. 4B) and Musashi-1 (Fig. 4C) (Mckay, 1997; Barres, 1999; Kaneko et al., 2000) and also to GFAP (Fig.4A) (Doetsch et al., 1999; Alvarez-Buylla et al., 

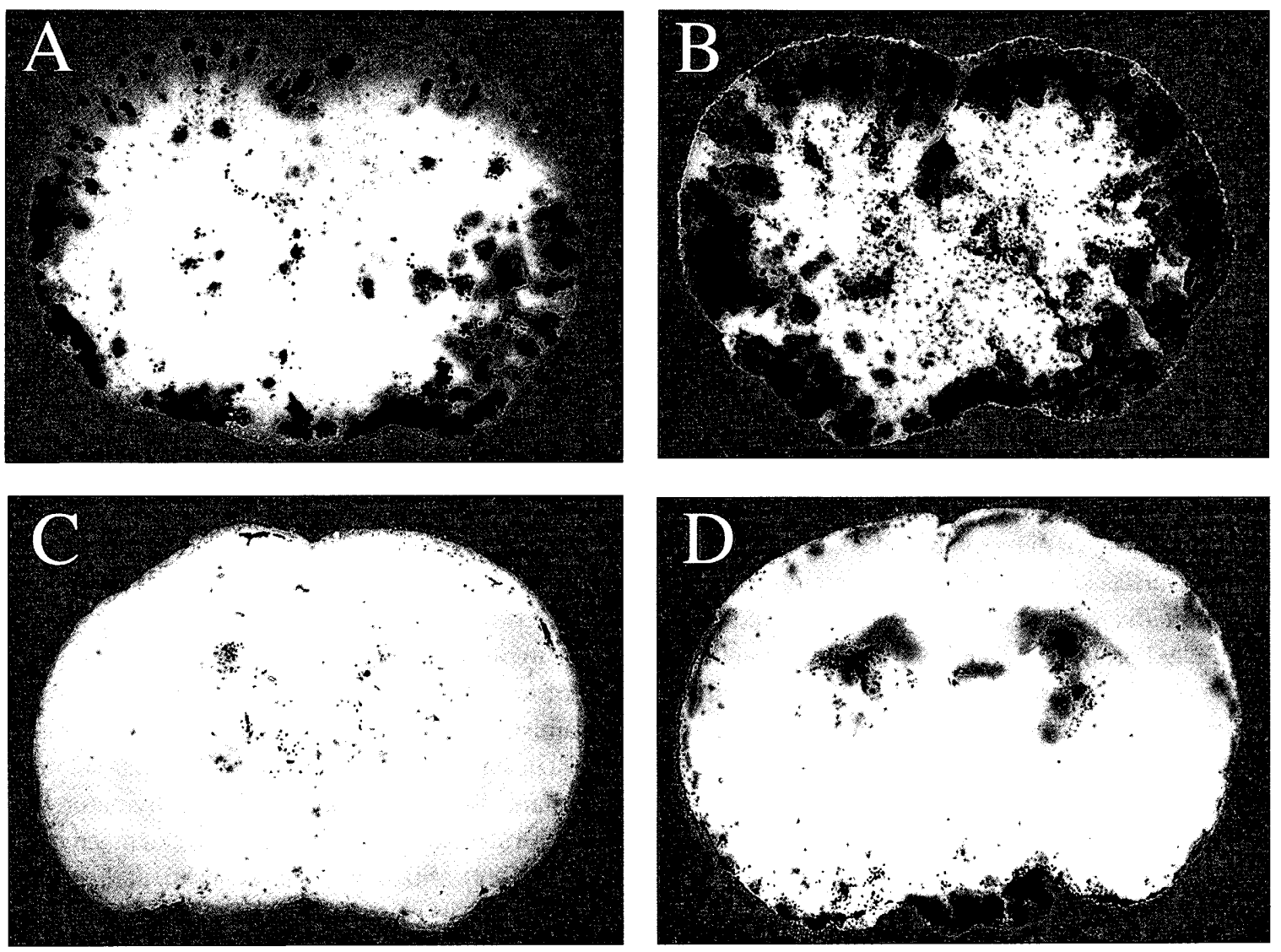

Fig. 3 Age-dependent changes of $\beta$-Gal expression in the brain slice cultures from mice of different ages after MCMV infection. The brain slice cultures from 0-day-old (A, B) and 21-day-old (C, D) BALB/c mice were infected with recombinant MCMV (RM461) $\left(5 \times 10^{6}\right.$ $\mathrm{PFU} / \mathrm{ml})$ by whole immersion, and cultured for $72 \mathrm{~h}(\mathbf{A}, \mathbf{C})$ or $120 \mathrm{~h}(\mathbf{B}, \mathbf{D})$. In the 0 -day-old slices $(\mathbf{A}, \mathbf{B})$, virus-infected cells were scattered all over the slices. In the 21 -day-old slices $(\mathbf{C}, \mathbf{D})$, virus-infected cells tended to be localized in the subventricular zone (SVZ) and the marginal regions of the cortex.


Fig. 4 Immunohistochemical analysis of X-Gal-stained brain slices using antibodies to neural progenitor cell markers. Brain slice cultures from 21-day-old mice were infected with RM461 and stained with X-Gal 3 days after infection. The sections were immunohistochemically stained using antibodies to GFAP (A), nestin (B), Musashi-1 (C). X-Gal-positive cells (blue) around the subventricular zone (SVZ) were double-stained with antibodies to GFAP (A), nestin (B), Musashi-1 (C). 
2001). Cells susceptible to MCMV infection in the SVZ were thought to be glial immature cells and neural progenitor cells, including neural stem cells. Kosugi et al. reported that MCMV infects EGF-responsive CNS stem/progenitor cells and inhibits the growth and DNA replication of stem/progenitor cell (Kosugi et al., 2000). Immature glial cells, including neural progenitor cells, in the SVZ and marginal area were the most susceptible to MCMV in brain slice cultures from neonatal mice, and the susceptibility declined as the number of immature glial cells decreased with age. These results suggest that the number of the immature glial cells may be a primary factor of the susceptibility of the brain to CMV infection in the acute infection stage. The brain slice culture is a useful method to analyze the susceptibility of the viruses or number of insults to the brain during different developing stages.

\section{IMMUNOLOGLICAL ASPECT OF THE BRAIN SLICE CULTURE}

The general view is that CMV is more damaging to the developing brain than to the mature brain because the systemic immune system is too immature during development to eliminate the CMV infection. The resistance is thought to be due to the development of the host's defense mechanisms such as those mediated by natural killer (NK) cells (Brutkiewicz and Welsh, 1995) and macrophages (Booss et al., 1989). These cells have been shown to fight CMV infections and the efficacy of these systems increases with development. In spite of the fact that the innate immune system's activation during cytomegalovirus infection in the developing mouse brain (Kosugi et al., 2002), there seems to be another aspect of the susceptibility of CMV to the brain. Recently van den Pol et al suggested that developing brain cells are inherently more susceptible to CMV infection, independent of the immune system. After intracerebral inoculation, the number of CMVinfected cells in neonatal brains was many times greater than in mature control or mature immunodepressed SCID mice, and the mortality rate of neonates was substantially greater than SCID or control adults (van den Pol et al., 2002). In order to know whether immune responses are associated with susceptibility to MCMV infection, we used the brain slice culture system. We compared the susceptibility of brain slices from BALB/c mice with that of slices from Beige-SCID mice. This immunocompromised strain is deficient in both $\mathrm{T}$ and $\mathrm{B}$ cell functions and has reduced natural killer cell activity. Previously we reported that immature glial cells proliferated when brain slices were cultured for a prolonged time and were susceptible to CMV (Kawasaki et al., 2002; Tsutusi et al., 2002). Brain slices from 21-day-old BALB/c and Beige-SCID mice were infected with the mutant MCMV (RM461). X-Gal staining was performed 3 days after infection. Unexpectedly the amount of virus-infected cells stained with X-Gal was lower in the Beige-SCID mice than in the BALB/c mice. This ten- dency was also observed in the slices cultured for any period prior to infection (Fig. 5). The ratios of X-Gal-expressing area to whole-slice area of Beige-SCID mice were lower than those observed in BALB/c mice when compared quantitatively. For comparison of the amount of neural progenitor cells in the brain sections between Beige-SCID and BALB/c mice, we counted the cells immunostained with the antibodies to GFAP, nestin and Musashi-1 in 0-hour-cultures and 14-daycultures prior to infection. The numbers of the cells stained for neural progenitor cell markers (GFAP, nestin and Musashi1) were significantly lower in Beige-SCID mice than in BALB/ c mice(data not shown). In this experimental model we confirmed that the number of the immature glial cells/ progenitor cells is a primary factor for susceptibility. The question remained why Beige-SCID mice showed lower proliferation rates of neural progenitor cells than normal strains of mice. Immunological factors such as cytokines might affect the proliferation of the neural progenitor cells in the brain slice. By observing reactivation in brain slice culture taken from 6 month-old mouse infected at the neonatal period, Tsutsui et al. proved that latent infection occurs in the mouse brain (Tsutsui et al., 2002). These experimental models show the intermittent reactivation of CMV that occurs long after birth in individuals with congenital CMV infection or in immunocompromised adults in the central nervous system. The neural stem/progenitor cells may play an important role in this mechanism.

\section{GENE TRANSFER INTO THE BRAIN SLICES}

In CMV infection, susceptibility to viral infection at the cellular level seems to be associated with transcriptional regulation rather than with viral receptors. The receptor for CMV has not been identified, although a few candidates have been reported (Nowlin et al., 1991). The IE gene promoter of MCMV, the activation of which is dependent on cellular transcription factors that bind to the DNA sequence of the enhancer/promoter (Griffiths and Grundy, 1987; Mocarski, 1996), was transferred into brain slice cultures using a gene gun. Activation of the promoter was observed mainly in immature glial cells, including neural progenitor cells, of the SVZ. The number of cells in which the IE promoter was activated decreased with the brain development, whereas the number of cells able to activate the promoter transferred by gene gun was increased by culturing a slice for a longer preinoculation period (Kawasaki et al., 2002). It is possible that the proliferation of cells, with the potential to activate this promoter, was associated differentiation stimulation of the susceptible cells from the stem/progenitor cells in the SVZ during the preinoculation period. This suggests that the susceptibility of neural cells to MCMV infections may be regulated at the level of transcription of the IE gene. In correlation with this, we 

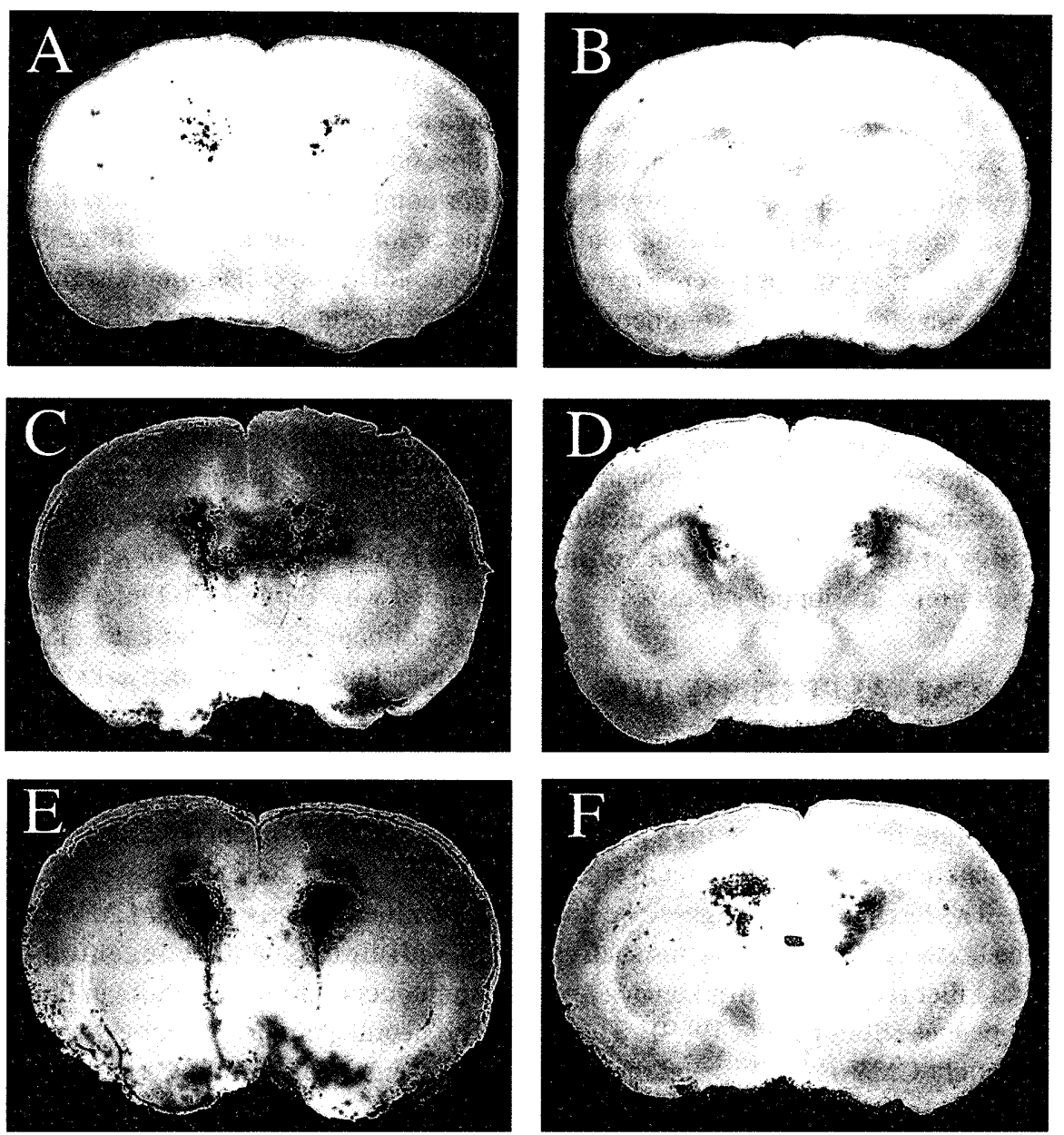

Fig. 5 Increase of infected cells by prolonged culturing prior to MCMV infection. Brain slices from 21-day-old BALB/c mice (A, C, E) and Beige-SCID mice $(\mathbf{B}, \mathbf{D}, \mathbf{F})$ were cultured for 0 day $(\mathbf{A}, \mathbf{B}), 7$ days $(\mathbf{C}, \mathbf{D}), 14$ days $(\mathbf{E}, \mathbf{F})$ prior to infection with mutant MCMV (RM461). The infected slices were incubated for 3 days, fixed and stained with X-Gal. The amount of X-Gal-positive cells increased when the culture period was longer prior to infection. The amount of virus-infected cells was lower in the Beige-SCID mice than that in $\mathrm{BALB} / \mathrm{c}$ mice.

reported that the IE promoter was activated in glial progenitor cells in the SVZ during brain development in transgenic mice (Aiba-Masago et al., 1999; Li et al., 2001). In addition to the gene gun, any viral vectors can transfer a gene of interest into brain slice cultures. Ehrengruber et al characterized recombinant Semliki Forest virus (SFV), adenovirus type 5 (Ad5), adeno-associated virus type 2 (AAV), lentivirus, and measles virus (MV) by their expression of green fluorescent protein (GFP) in rat hippocampal slice cultures (Ehrengruber et al., 2001). van den pol et al. investigated the possibility of cytomegalovirus as a useful vector for gene transfer to the brain (van den pol et al., 2000).

\section{FOR FURTHER STUDY}

The incidence of CMV-induced neurological problems has been estimated in $0.1 \%$ of births, with a possibility of subtle problems, such as learning deficits, in infected children. Synaptic roles for learning and behavioral disorders are being re- vealed. Synapses form the basic currency of information exchange between neurons and underlie the basic physiological function of circuits throughout the brain. In 1973 Bliss and Lomo by using brain slice made the remarkable discovery that major synaptic pathways in the hippocampus undergo a longterm form of synaptic plasticity (long-term potentiation, LTP) in response to a burst of high-frequency stimulation (Bliss and Lomo 1973). Patients who suffered from CMV brain infection with no morphological deformity of the CNS might have synaptic plasticity disorders causing learning disabilities or behavioral disorders. A brain slice culture using the electrophysiological method would be useful to reveal these disorders.

\section{CONCLUSION}

Cytomegalovirus (CMV) is the most common infectious cause of congenital anomalies of the brain and also causes brain damage in immunocompromised individuals. Pathology of 
CMV infection to the brain is highly associated with unique brain architecture, cell composition, migration and immune system. Studying CMV pathogenesis in the brain inevitably leads to the recent hot topics in the neuroscience world such as neural stem cell, migration, and apoptosis. Through CMV infection to the brain we can observe brain dynamic movements and functions. The brain slice system has characteristics more similar to in vivo than dissociated cells. The brain slice system is a useful method to investigate congenital and acquired CMV infection to the brain. Even though there are great advantages to using brain slice cultures, there are some disadvantages. Brain slice cultures are not a perfect model to represent in vivo phenomenon. Blood supply and natural immune responses seen in vivo are missing and culture-bias may considerably affect structural changes. The information and phenomenon obtained from the brain slice cultures should be compared with in vivo systems and dissociated cell culture systems.

Congenital anomaly of the brain might have started from observing the deformity of the brain. But recently the definition of congenital anomaly has been broadened to psychological and behavior disorders without particular morphological change of the brain. CMV may be one of the candidates for the cause of these disorders. Neural plasticity examined by electrophysiologically in the brain slice may play an important role in these areas. The brain slice culture system will hopefully give us new findings for congenital anomaly of the brain in the future.

\section{ACKNOWLEDGEMENTS}

We thank Mitsue Kawashima, Hiromi Suzuki and Masaaki Kaneta for excellent technical assistance. We thank Dr. E.S. Mocarski, Department of Microbiology and Immunology, Stanford University School of Medicine, for providing the recombinant MCMV (RM461). We also thank Dr. S. Sakakibara and Dr. H. Okano, Department of Physiology, Keio University School of Medicine, for providing the monoclonal antibody to Musashi-1. This work was supported in part by a grant (no. 10670284) from the Ministry of Education, Science, and Culture, Japan.

\section{REFERENCES}

Aiba-Masago S, Baba S, Li RY, Shinmura Y, Kosugi I, Arai Y, Nishimura M, Tsutsui Y (1999) Murine cytomegalovirus immediate-early promoter directs astrocyte-specific expression in transgenic mice. Am J Pathol, 154: 735-743.

Alvarez-Buylla A, Garcia-Verdugo JM, Tramontin AD (2001) A unified hypothesis on the lineage of neural stem cells. Nat Rev Neurosci, 2: 287-293.

Bale JF (1984) Human cytomegalovirus infection and disorders of the nervous system. Arch Neurol, 41: 310-320.
Barres BA (1999) A new role for glia: generation of neurons. Cell, 97: 667-670.

Becroft DMO (1981) Prenatal cytomegalovirus infection: Epidemilolgy, pathology, pathogenesis. In: Rosenberg HS and Bernstein $\mathbf{J}$ (eds) Perspectives in Pediatric Pahtology. Massohn, New York, pp 203-241.

Bergmann A, Tugentman M, Shilo BZ, Steller H (2002) Regulation of cell number by MAPK-dependent control of apoptosis: a mechanism for trophic survival signaling. Dev Cell, 2: 159-170.

Billingsley ML, Kincaid RL (1997) Regulated phosphorylation and dephosphorylation of tau protein: effects on microtubule interaction, intracellular trafficking and neurodegeneration. Biochem J, 323: 577-591. Review.

Bliss TV, Lomo T (1973) Long-lasting potentiation of synaptic transmission in the dentate area of the anaesthetized rabbit following stimulation of the perforant path. $J$ Physiol, 232: $331-56$.

Booss J, Dann PR, Griffith BP, Kim JH (1989) Host defense response to cytomegalovirus in the central nervous system. Am J Pathol, 134: 71-78.

Breder J, Sabelhaus CF, Opitz T, Reymann KG, Schroder UH (2000) Inhibition of different pathways influencing $\mathrm{Na}(+)$ homeostasis protects organotypic hippocampal slice cultures from hypoxic/hypoglycemic injury. Neuropharmacology, 39: 1779-1787.

Britt WJ, Alford CA (1996) Cytomegalovirus. Virology, ed 3. Edited by Fields BN, Knipe DM, Howley PM. Philadelphia, Lippincott-Raven, 2493-2523.

Brutkiewicz RR, Welsh RM (1995) Major histocompatibility complex class I antigens and the control of viral infections by natural killer cells. J Virol, 69: 3967-3971.

Cinque P, Marenzi R, Ceresa D (1997) Cytomegalovirus infections of the nervous system. Intervirology, 40: 85-97.

Conboy TJ, Pass RF, Stagno S, Britt WJ, Alford CA, McFarland CE, Boll TJ (1986) Intellectual development in school-aged children with asymptomatic congenital cytomegalovirus infection. Pediatrics, 77: 801-806.

DeBiasi RL, Kleinschmidt-DeMasters BK, Richardson-Burns S, Tyler KL (2002) Central nervous system apoptosis in human herpes simplex virus and cytomegalovirus encephalitis. J Infect Dis, 186: 1547-1557.

Demmler GJ (1991). Infectious Diseases Society of America and Centers for Disease Control. Summary of a workshop on surveillance for congenital cytomegalovirus disease. Rev Infect Dis, 13: 315-329.

Doetsch F, Caille I, Lim DA, Garcia-Verdugo JM, AlvarezBuylla A (1999) Subventricular zone astrocytes are neural stem cells in the adult mammalian brain. Cell, 97: 703-716.

Durkin JP, Tremblay R, Chakravarthy B, Mealing G, Morley P, Small D, Song D (1997) Evidence that the early loss of membrane protein kinase $\mathrm{C}$ is a necessary step in the excitatory amino acid-induced death of primary cortical neu- 
rons. J Neurochem, 68: 1400-1412.

Ehrengruber MU, Hennou S, Bueler H, Naim HY, Deglon N, Lundstrom K (2001) Gene transfer into neurons from hippocampal slices: comparison of recombinant Semliki Forest Virus, adenovirus, adeno-associated virus, lentivirus, and measles virus. Mol Cell Neurosci, 17: 855-871.

Ghosh A, Greenberg ME (1995) Calcium signaling in neurons: molecular mechanisms and cellular consequences. Science, 268: 239-247. Review.

Griffiths PD, Grundy JE (1987) Molecular biology and immunology of cytomegalovirus. Biochem J, 241: 313-324.

Hayashi K, Eizuru Y, Sato S, Minamishima Y (1985) The role of NK cell activity in age-dependent resistance of mice to murine cytomegalovirus infection. Microbiol Immunol, 29: 939-950.

Ho M (1991) Congenital and perinatal human cytomegalovirus infection. In: Ho M (ed) Cytomegalovirus: biology and infection. Plenum Press, New York, pp 205-277.

Kaneko Y, Sakakibara S, Imai T, Suzuki A, Nakamur a Y, Sawamoto K, Ogawa Y, Toyama Y, Miyata T, Okano H (2000) Musashil: an evolutionally conserved marker for CNS progenitor cells including neural stem cells. Dev Neurosci, 22: 139-153.

Kawasaki H, Kosugi I, Arai Y, Tsutsui Y (2002) The amount of immature glial cells in organotypic brain slices determines the susceptibility to murine cytomegalovirus infection. Lab Invest, 82: 1347-1358.

Kosugi I, Kawasaki H, Arai Y, Tsutsui Y (2002) Innate immune responses to cytomegelovirus infection in the developing mouse brain and their evasion by virus-infected neurons. Am J pathol, 161: 919-928.

Kosugi I, Shinmura Y, Kawasaki H, Arai Y, Li RY, Baba S, Tsutsui Y (2000) Cytomegalovirus infection of the central nervous system stem cells from mouse embryo: a model for developmental brain disorders induced by cytomegalovirus. Lab Invest, 80: 1373-1383.

Kosugi I, Shinmura Y, Li RY, Aiba-Masago S, Baba S, Miura K, Tsutsui Y (1998) Murine cytomegalovirus induces apoptosis in non-infected cells of the developing mouse brain and blocks apoptosis in pirmary neuronal culture. Acta Neuropathol (Berl), 96: 239-247.

Kristensen BW, Noraberg J, Zimmer J (2001) Comparison of excitotoxic profiles of ATPA, AMPA, KA and NMDA in organotypic hippocampal slice cultures. Brain Res, 917: 21-44.

Kumar ML, Nankervis GA (1978) Experimental congenital infection with cytomegalovirus: A guinea pig model. $J$ infect Dis, 138: 650-654.

Lammens M (2000) Neuronal migration disorders in man. Eur J Morphol, 38: 327-333.

Li RY, Baba S, Kosugi I, Arai Y, Kawasaki H, Shinmura Y, Sakakibara S, Okano H, Tsutsui Y (2001) Activation of murine cytomegalovirus immediate-Early promoter in ce- rebral ventricular zone and glial progenitor cells in transgenic mice. Glia, 35: 41-52.

Li RY, Tsutsui Y (2000) Growth retardation and microcephaly induced in mice by placental infection with murine cytomegalovirus. Teratology, 62: 79-85.

Light KE, Belcher SM, Pierce DR (2002) Time course and manner of Purkinje neuron death following a single ethanol exposure on postnatal day 4 in the developing rat. $\mathrm{Neu}$ roscience, 114: 327-37.

Lo DC, McAllister AK, Katz LC (1994) Neuronal transfection in brain slices using particle-mediated gene transfer. Neuron, 13: 1263-1268.

London WT, Martinez AJ, Houff SA (1986) Experimental congenital disease with simian cytomegalovirus in rhesus monkeys. Teratology, 33: 323-331.

Luetjens CM, Bui NT, Sengpiel B, Munstermann G, Poppe M, Krohn AJ, Bauerbach E, Krieglstein J, Prehn JH (2000) Delayed mitochondrial dysfunction in excitotoxic neuron death: cytochrome c release and a secondary increase in superoxide production. J Neurosci, 20: 5715-5723.

McKay R (1997) Stem cells in the central nervous system. Science, 276: $66-71$.

Mocarski ES Jr (1996) Cytomegalovirus and their replication. In: Field BN, Knipe DM, Howley PM (eds) Virology, 3rd edn. Lippincott-Raven, Philadelphia, pp 2447-2449.

Morris MC, Depollier J, Mery J, Heitz F, Divita G (2001) A peptide carrier for the delivery of biologically active proteins into mammalian cells. Nat Biotechnol, 19: 1173-1176.

Moskowitz SI, Basu SB, Bergold PJ (2001) Chronic and cyclical neuronal loss in hippocampal slice cultures following transient inhibition of the type 1 isoform of superoxide dismutase. Brain Res, 913: 207-219.

Noer H, Kristensen BW, Noraberg J, Zimmer J, Gramsbergen JB (2002) 3-Nitropropionic acid neurotoxicity in hippocampal slice cultures: developmental and regional vulnerability and dependency on glucose. Exp Neurol, 176: 237246.

Noraberg J, Kristensen BW, Zimmer J (1999) Markers for neuronal degeneration in organotypic slice cultures. Brain Res Brain Res Protoc, 3: 278-290.

Nowlin DM, Cooper NR, Compton T (1991) Expression of a human cytomegalovirus receptor correlate with infectivity of cells. J Virol, $\mathbf{6 5}$ : 3114-3121.

O'Rourke NA, Chenn A, McConnell SK (1997) Postmitotic neurons migrate tangentially in the cortical ventricular zone. Development, 124: 997-1005.

Pass RF, Stagno S, Myers GJ, Alford CA (1980) Outcome of symptomatic congenital cytomegalovirus infection: results of long-term longitudinal follow-up. Pediatrics, 66: 758762.

Pringle AK, Angunawela R, Wilde GJ, Mepham JA, Sundstrom LE, Iannotti F (1997) Induction of $72 \mathrm{kDa}$ heatshock protein following sub-lethal oxygen deprivation in 
organotypic hippocampal slice cultures. Neuropathol Appl Neurobiol, 23: 289-298.

Rakic P (1990) Principles of neural cell migration. Experientia, 46: $882-891$.

Roberts JS, O'Rourke NA, McConnes SK (1993) Cell migration in cultured cerebral cortical slices. Dev Bio, 155: 396408.

Runden E, Seglen PO, Haug FM, Ottersen OP, Wieloch T, Shamloo M, Laake JH (1998) Regional selective neuronal degeneration after protein phosphatase inhibition in hippocampal slice cultures: evidence for a MAP kinase-dependent mechanism. J Neurosci, 18: 7296-7305

Schwarze SR, Ho A, Vocero-Akbani A, Dowdy SF (1999) In vivo protein transduction: delivery of a biologically active protein into the mouse. Science, 285: 1569-1572.

Shinmura Y, Aiba-Masago S, Kosugi I, Li RY, Baba S, Tsutsui Y (1997a) Differential expression of the immediate-early and early antigens in neuronal and glia cells of developing mouse brains infected with murine cytomegalovirus. Am J pathol, 151: 1331-1340.

Shinmura Y, Kosugi I, Aiba-Masago S, Baba S, Yong LR, Tsutsui Y (1997b) Disordered migration and loss of virusinfected neuronal cells in developing mouse brains infected with murine cytomegalovirus. Acta Neuropathol (Berl), 93: 551-557.

Shinmura Y, Kosugi I, Kaneta M, Tsutsui Y (1999) Migration of virus-infected neuronal cells in cerebral slice cultures of developing mouse brains after in vitro infection with murine cytomegalovirus. Acta Neuropathol (Berl), 98: 590-596.

Stagno S, Pass RF, Cloud G, Britt WJ, Henderson RE, Walton PD, Veren DA, Page F, Alford CA (1986) Primary cytomegalovirus infection in pregnancy. Incidence, transmission to fetus, and clinical outcome. JAMA, 256: 1904-1908.

Strijbos PJ, Leach MJ, Garthwaite J (1996) Vicious cycle involving $\mathrm{Na}+$ channels, glutamate release, and NMDA receptors mediates delayed neurodegeneration through nitric oxide formation. $J$ Neurosci, 16: 5004-5013.

Tasker RC, Coyle JT, Vornov JJ (1992) The regional vulnerability to hypoglycemia-induced neurotoxicity in organotypic hippocampal culture: protection by early tet- rodotoxin or delayed MK-801. J Neurosci, 12: 4298-4308.

Tsutsui Y (1995) Developmental disorders of the mouse brain induced by murine cytomegalovirus: animal models for congenital cytomegalovirus infection. Pathol Int, 45: 91 102.

Tsutsui Y, Kashiwai A, Kawamura N, Kadota C (1993) Microphthalmia and cerebral atrophy induced in mouse embryo by infection with murine cytomegalovirus in midgestation Am J Patho, 143: 804-812.

Tsutsui Y, Kawasaki H, Kosugi I (2002) Reactivation of latent cytomegalovirus infection in mouse brain cells detected after transfer to brain slice cultures. $J$ virol, 76: 7247-7254.

Tsutsui Y, Kosugi Y, Shinmura Y, Nagahama M (1997) Congenital Infection and Disorder of Brain Development: With Special Reference to Congenital Cytomegalovirus Infection. Cong Anom, 37: 1-14.

Tsutsui Y, Nagahama M, Mizutani A (1999) Neuronal migraion disorder in cerebral palsy. Neuropathology, 19: 14-27.

Tsutsui Y, Naruse I (1987) Murine cytomegalovirus infection of cultured mouse embryos. Am J Pathol, 127: 262-270.

van den Pol AN, Reuter JD, Santarelli JG (2002) Enhanced cytomegalovirus infection of developing brain independent of the adaptive immune system. $J$ Virol, 76: 8842-8854.

van Den Pol AN, Vieira J, Spencer DD, Santarelli JG (2000) Mouse cytomegalovirus in developing brain tissue: analysis of 11 species with GFP-expressing recombinant virus. $J$ Comp Neurol, 427: 559-580.

Weller TH (1971) The cytomegalovirus: ubiquitous agents with protean clinical manifestations. $N$ Eng J Med, 285: 203-214.

Wieloch T, Hu BR, Boris-Moller A, Cardell M, Kamme F, Kurihara J, Sakata K (1996) Intracellular signal transduction in the postischemic brain. Adv Neurol, 71: 371-387.

Yin HZ, Sensi SL, Ogoshi F, Weiss JH (2002) Blockade of $\mathrm{Ca} 2+$-permeable AMPA/kainate channels decreases oxygen-glucose deprivation-induced $\mathrm{Zn} 2+$ accumulation and neuronal loss in hippocampal pyramidal neurons. $J$ Neurosci, 22: 1273-1279.

Yuan J, Yankner BA (2000) Apoptosis in the nervous system. Nature, 407: 802-809. Review. 